\title{
Espólios, livros e vivências pessoais: lendo a cultura do outro, relendo minha própria cultura
}

\section{Desde o principio...}

Foi o contato precoce com periódicos que me levou a eleger esse objeto como base de minhas pesquisas acadêmicas. Ainda na iniciação científica, o trabalho com a $2^{\mathrm{a}}$ série da revista A Águia - palco do "Saudosismo" e dos primeiros textos publicados pelo poeta Fernando Pessoa despertou meu interesse pela literatura e cultura portuguesas. No mestrado, pesquisei a revista carioca Terra de Sol, que era dirigida pelo poeta paranaense Tasso da Silveira e pelo editor e jornalista português, Álvaro Pinto, que fora secretário da revista portuense.

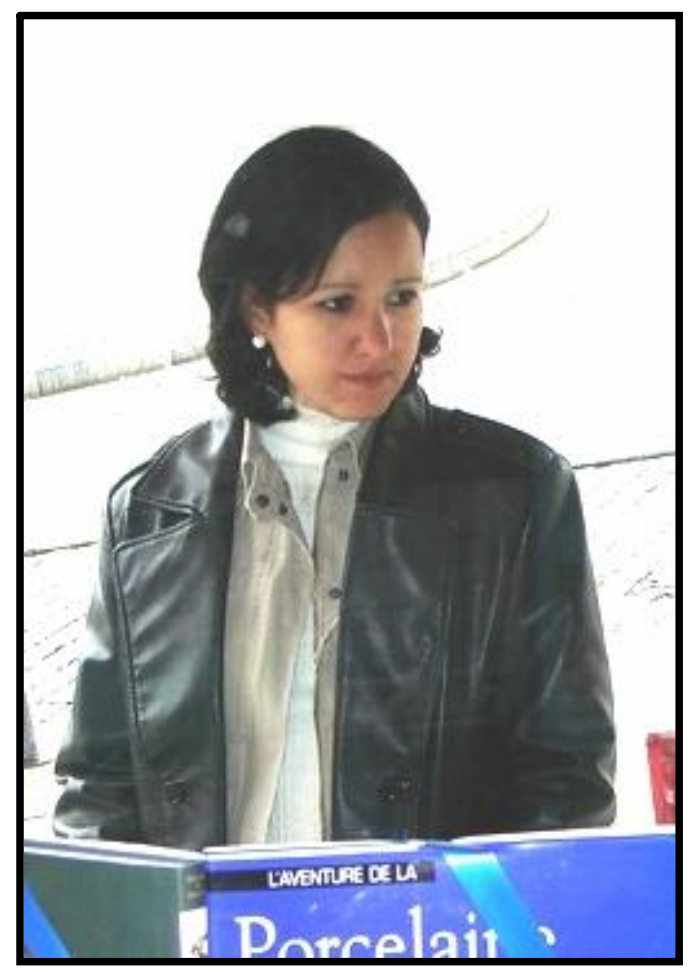

Agora, no doutorado, a idéia é verificar as relações entre esses dois periódicos, acrescentando à pesquisa a revista lisboeta Seara Nova, que é fruto de uma cisão entre os membros da sociedade "Renascença Portuguesa”.

Desde o início do doutorado, em 2004, eu e meu orientador concordamos que seria necessário realizar parte das pesquisas em Portugal. Por isso, em 2006, enviei projeto para a FAPESP - entidade da qual sou bolsista - solicitando permissão para realizar a viagem

\footnotetext{
${ }^{1}$ Doutoranda em Estudos Comparados de Literaturas de Língua Portuguesa, FFLCHUSP. Pesquisa: Convergências e Divergências: Revistas literárias em perspectiva - $A$ Águia, Seara Nova e Terra de Sol.
} 
com os recursos da Reserva Técnica. A partir da aprovação dessa proposta, teve início o planejamento da viagem.

\section{Antes de embarcar}

Levando em consideração a quantidade de dinheiro disponível e o volume das pesquisas que seriam realizadas, decidi que deveria permanecer quatro meses em Portugal. Ainda no Brasil, além de elaborar um cronograma detalhado de todas as pesquisas que seriam realizadas, foi fundamental decidir algumas questões práticas relacionadas à viagem. As mais importantes foram: a compra de passagens, o local de hospedagem em Lisboa e a melhor forma de lidar com o dinheiro enquanto estivesse por lá.

No início de novembro de 2006, comprei as passagens, pois elas realmente costumam custar menos quando são adquiridas com antecedência. Tendo em conta, exclusivamente, o critério preço, escolhi a companhia aérea espanhola Ibéria. Mais tarde, essa decisão se revelou um erro.

Com a ajuda do meu orientador, entrei em contato com uma professora brasileira que mora em Lisboa. Esta, por sua vez, me indicou uma amiga - Maria Manuel - que costuma alugar um quarto para pesquisadores. Além de ser mais barato e prático que o aluguel de um apartamento, o contato diário com uma portuguesa possibilitou que eu tivesse várias informações que facilitaram muito o meu dia-a-dia e permitiram que eu aproveitasse ao máximo a estadia em terras lusitanas. Isso, sem contar a grande amizade que surgiu dessa experiência.

Quanto ao dinheiro, depois de pesquisar muito e ouvir várias opiniões decidi levar apenas duzentos Euros na carteira e um cartão de crédito internacional. Com o cartão é possível retirar dinheiro nos caixas eletrônicos - que são facilmente encontrados em toda a Europa - e fazer compras na maioria dos estabelecimentos. 
Somente duas semanas antes de embarcar, descobri que para ficar em Portugal (e na União Européia) por mais de três meses, seria preciso conseguir um visto junto à embaixada portuguesa. Como não havia mais tempo hábil para isso, decidi viajar sem o visto e tentar resolver esse problema por lá.

\section{Fevereiro}

Em fevereiro de 2007, finalmente, embarquei. Essa viagem representou a concretização de um sonho que fora, desde sempre, acalentado por meu pai - filho de um português que, tendo emigrado para o Brasil ainda jovem, não tivera mais oportunidade de retornar a seu país.

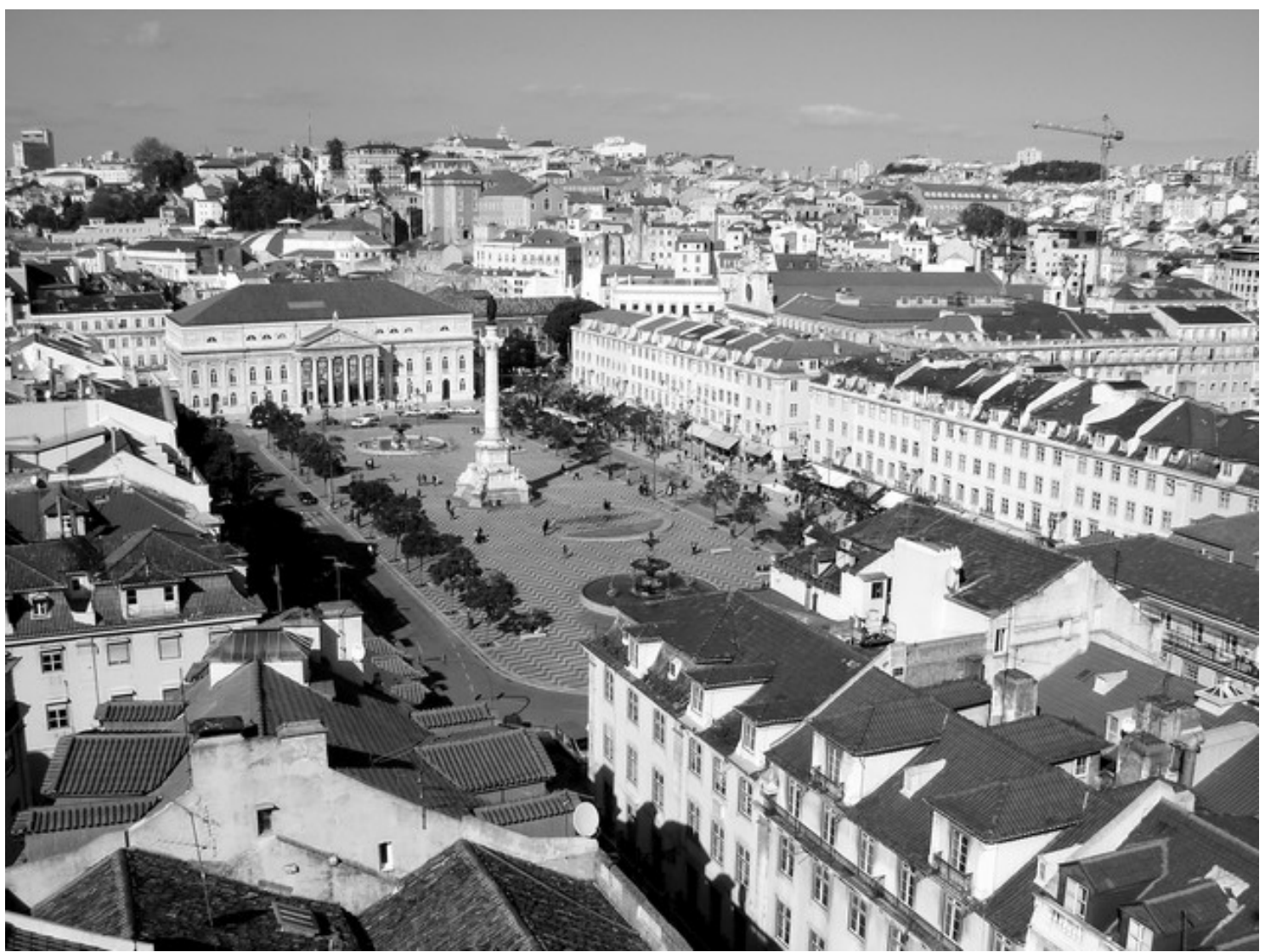

Centro de Lisboa (foto da autora)

Assim que cheguei a Portugal, tratei de solucionar questões práticas, como a aquisição do passe Lisboa Viva - que dá direito ao uso 
ilimitado do sistema de transportes públicos da cidade - e a confecção do cartão de usuário da Biblioteca Nacional. No meu caso, foi preciso pedir uma autorização especial para pesquisar os espólios de alguns intelectuais envolvidos com as revistas estudadas.

Meus primeiros dias em Lisboa foram de adaptação àquela realidade totalmente nova para mim. Conheci duas professoras brasileiras - Beatriz Weigert e Vânia Chaves - que me acolheram com bastante carinho e de maneira extremamente generosa. Também entrei em contato, por e-mail, com o supervisor de minha pesquisa, Prof. Dr. Ernesto Rodrigues, que me deu orientações, levou-me à Biblioteca da Faculdade de Letras e indicou a leitura de algumas obras consideradas fundamentais para meus estudos.

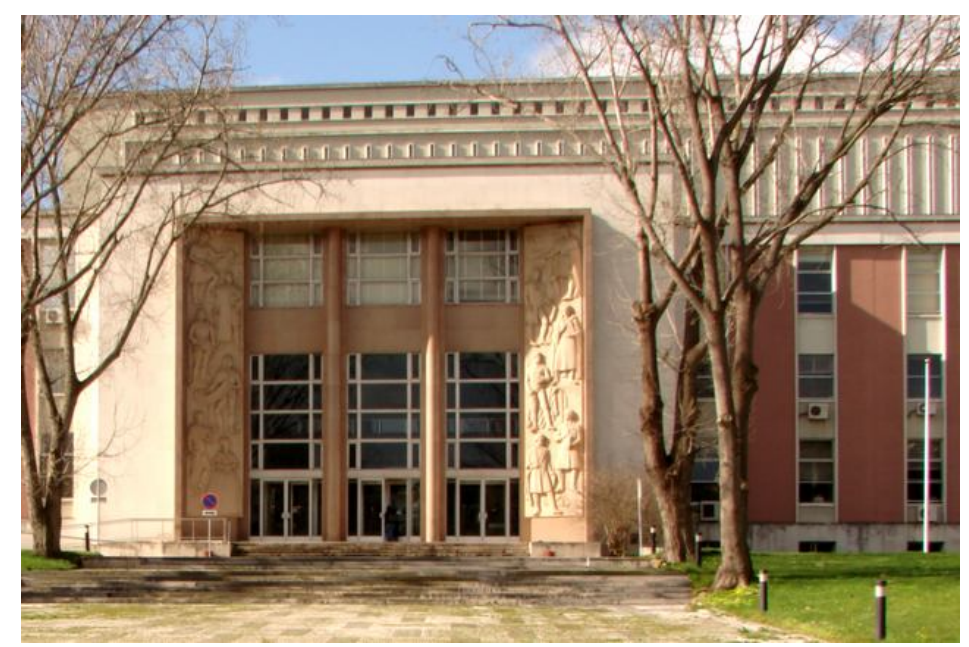

Biblioteca Nacional (foto da autora)

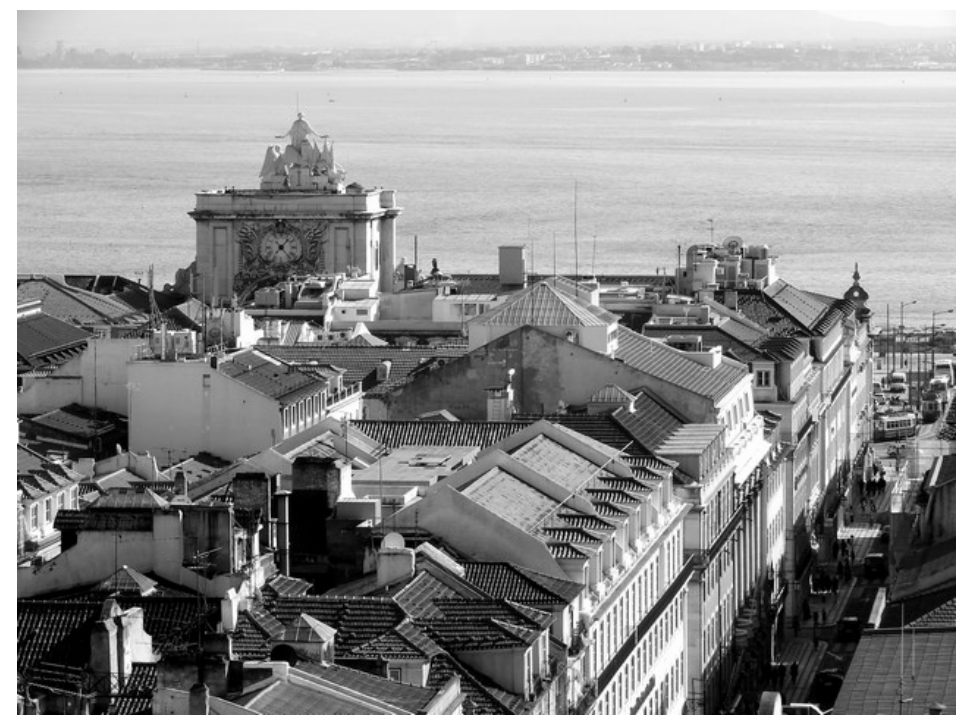

A Baixa e o Tejo (foto da autora)
Ainda na primeira semana, comecei a trabalhar todos os dias na $\mathrm{BN}$, onde dividia meu tempo entre os espólios e as pesquisas na seção de referência, lendo dissertações, teses e obras críticas e literárias referentes às minhas "investigações". Somente nos fins de semana, eu saía para conhecer as atrações turísticas de Lisboa e fazer pequenas viagens pelos arredores da cidade. E nos feriados, era possível conhecer lugares um pouco mais distantes. No carnaval, por exemplo, fui para Sevilha, que fica a apenas 5 horas de ônibus de Lisboa. 


\section{Março}

Em março, a Faculdade de Letras da Universidade de Lisboa abriu inscrições para o "Curso Livre de Literatura Portuguesa Contemporânea", ministrado por professores do corpo discente da universidade e, também, por alguns convidados - dentre professores e escritores. Aprendi muito nessas aulas, pois entrei em contato com autores até então desconhecidos para mim. Em meus passeios nos fins de semana, passei a frequentar com mais assiduidade as livrarias e alfarrabistas do belíssimo Bairro Alto de Lisboa. dessa forma, adquiri algumas obras importantes para a tese e muitas outras para minha biblioteca particular.

Nesse momento, então, eu já estava bastante familiarizada com a Biblioteca, e transitava bem entre os setores de periódicos, espólios e o de obras de referência. Eu almoçava no restaurante de lá e, às vezes, ia até a cantina da Faculdade de Letras para dar uma variada no "tempero" lusitano.

\section{Abril}

Em uma das orientações do trabalho, o supervisor da pesquisa sugeriu que eu fosse ao Porto fazer uma entrevista com o editor da Caixotim - o Dr. Paulo Samuel - que foi autor de uma importante obra sobre a sociedade "Renascença Portuguesa". Combinada a entrevista, comprei a passagem e fui de comboio (trem) em direção ao Norte de Portugal. Parei em Coimbra, a fim de conhecer a "Quinta das Lágrimas, Fonte dos Amores”, cenário dos amores proibidos de D. Pedro e D. Inês de Castro, e título de um importante poema da $2^{\mathrm{a}}$ série de A Águia. Passei uma tarde vendo o Mondego, a belíssima Universidade e algumas atrações do lugar.

Em seguida, dirigi-me para a encantadora cidade do Porto. Lá, aproveitei para conhecer a Biblioteca Municipal e pesquisar algumas obras que não existiam em Lisboa; conheci a linda livraria Lello \& 
Irmão, duas das Caves de Vinho do Porto e realizei, finalmente, a entrevista marcada com o editor portuense.

\section{A entrevista serviu} para que eu pudesse discutir algumas questões relacionadas à importância da Associação de intelectuais sobre a qual escrevera esse editor, e para tentar perceber qual o significado da retomada desse projeto, nos anos oitenta, com o surgimento da revista Nova Renascença.

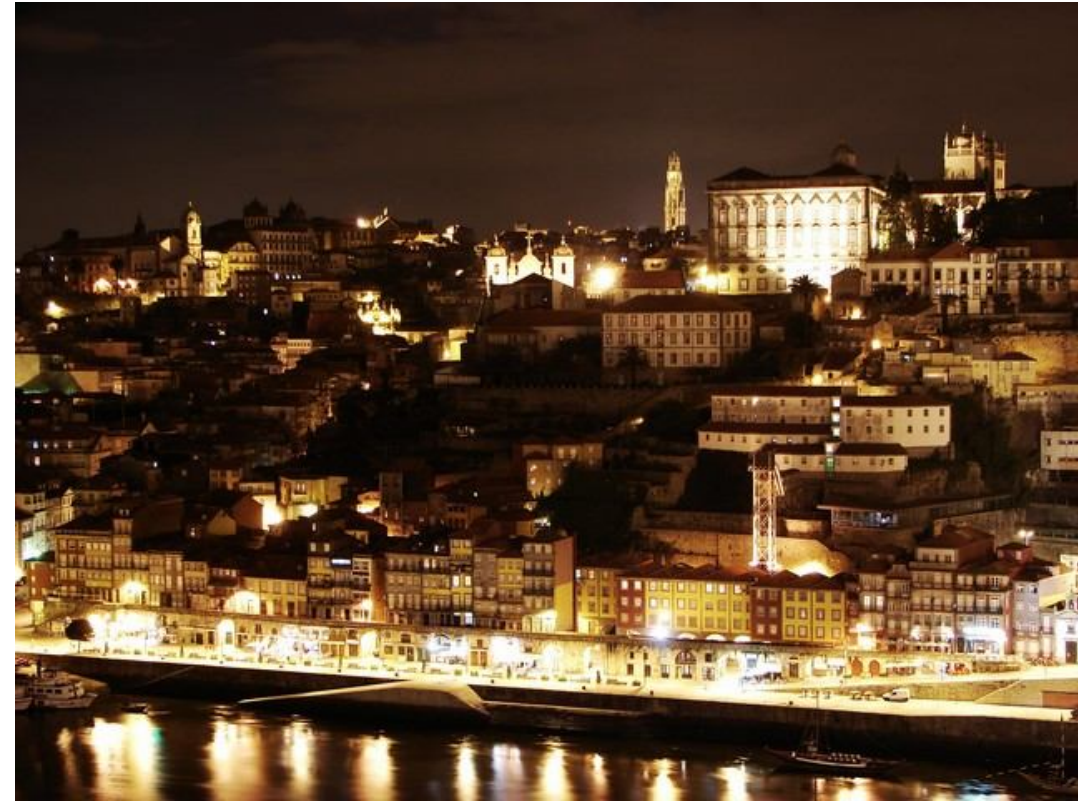

O Porto à noite (foto da autora)

Ainda no mês de abril, no feriado da páscoa, fiz uma viagem de 3 dias, a Paris e, logo em seguida, participei de um congresso em Bruxelas, na Bélgica.

\section{Maio}

O mês de Maio trouxe, para mim, uma descoberta emocionante: encontrei no espólio de Raul Proença - membro da "Renascença Portuguesa”, um dos diretores da Seara Nova e também funcionário da Biblioteca Nacional, no início do século XX - uma carta manuscrita de Fernando Pessoa pedindo a este intelectual que interviesse no processo de registro da revista Orpheu. Essa carta, inédita em livro, não era conhecida nem mesmo por um dos editores das obras completas de Pessoa, que também costumava realizar pesquisas diárias nos espólios na BN.

Ainda no início de maio, completavam-se três meses de minha permanência na Europa. Para ficar mais um mês, como planejado, seria 
preciso conseguir um visto. No Serviço de Estrangeiros e Fronteiras, me deparei com um pequeno problema. Minha entrada na UE tinha sido carimbada em meu passaporte pela Espanha. Por isso, para conseguir a prorrogação de permanência em Portugal seria preciso pagar uma multa por não haver informado às autoridades lusitanas da minha entrada no país. No final, o valor dessa multa foi superior à diferença no preço das passagens pela companhia aérea espanhola.

\section{A feira do livro}

Um evento importante, para nós pesquisadores, e que acontece no final desse mês, é a grande Feira do Livro, no Parque Eduardo Sétimo, Centro de Lisboa. Lá é possível adquirir obras de várias editoras portuguesas a preços bem interessantes.

\section{Junho}

Já pensando no meu retorno, quando fui para Portugal procurei levar a menor quantidade possivel de roupas em uma única mala. Dessa forma, na volta, pude trazer uma mala extra - só com livros e cópias em xerox - sem exceder o limite de peso das bagagens.

Finalizado o "Curso Livre de Literatura Portuguesa" e cumpridas todas as etapas presentes no meu Cronograma de Estudos, retornei, então, ao Brasil.

\section{Um breve balanço}

Uma viagem como essa possibilita uma grande ampliação do conhecimento. Esse encontro com um país estrangeiro produz, como é sabido, um efeito de dupla via: você lê a cultura do outro, a partir da sua própria; mas passa a reler a sua, com base nos novos conhecimentos adquiridos. 
Para os estudantes de literaturas em língua portuguesa, nada melhor que ter a oportunidade de realizar estudos na Biblioteca Nacional e ter acesso a obras literárias, espólios, dissertações e teses acessiveis a nós, apenas, nessa importante instituição portuguesa; e nada melhor, também, que ver monumentos, castelos e entrar em contato direto com a cultura e o falar lusitanos - exercícios esses que, com toda a certeza, contribuem imensamente para o nosso trabalho de pesquisa.

São Paulo, outubro de 2007

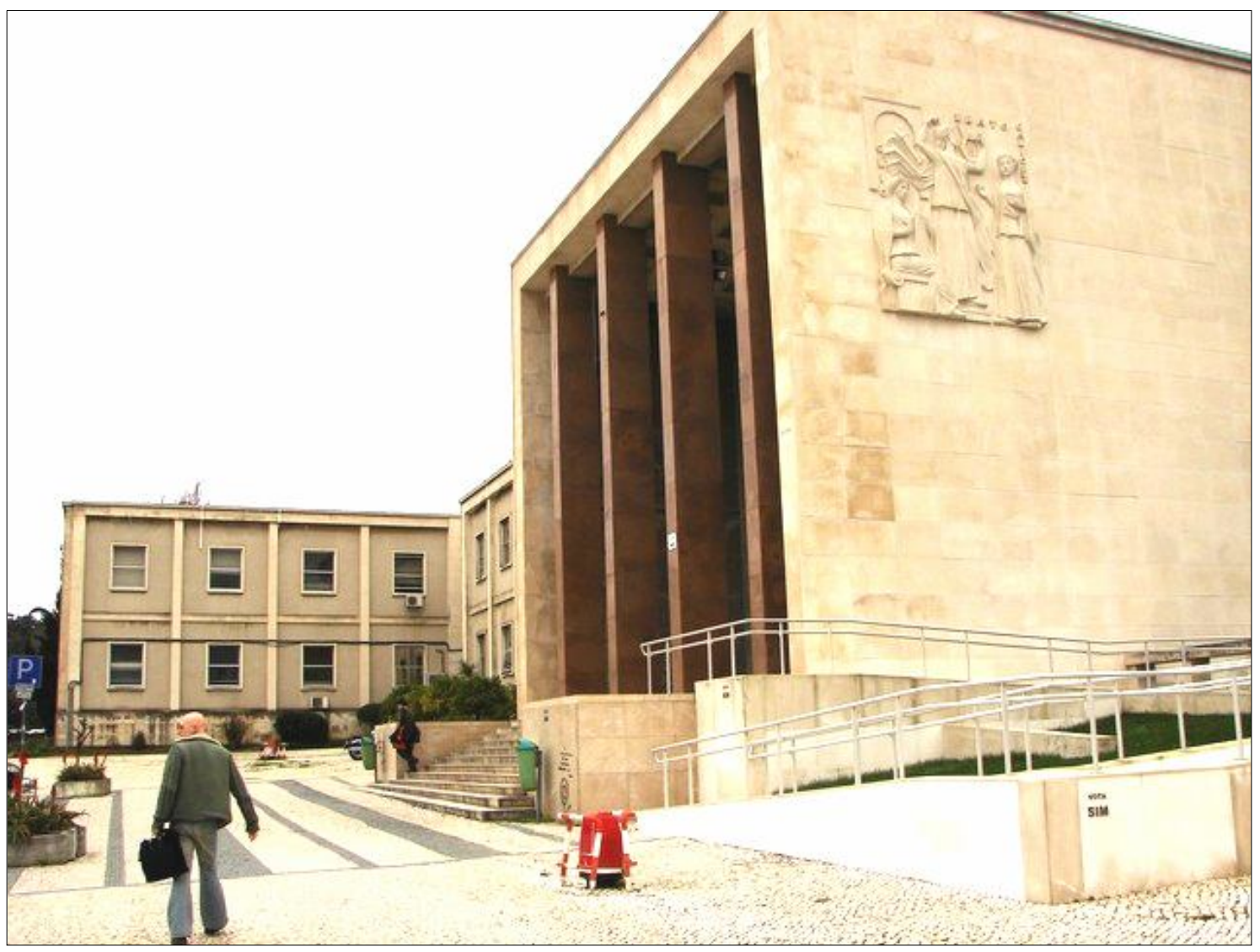

Faculdade de Letras da Universidade de Lisboa (foto da autora) 